\title{
FORCED INFORMATION DISCLOSURE AND THE FALLACY OF TRANSPARENCY IN MARKETS
}

\author{
TIMOTHY N. CASON and CHARLES R. PLOTT*
}

\begin{abstract}
A theory advanced in regulatory hearings holds that market performance will be improved if one side of the market is forced to publicly reveal preferences. For example, wholesale electricity producers claim that retail electricity consumers would pay lower prices if wholesale public utility demand is disclosed to producers. Experimental markets studied here featured decentralized, privately negotiated contracts, typical of the wholesale electricity markets. Two conclusions emerge: (1) such markets generally converge to the competitive equilibrium and (2) forced disclosure works to the disadvantage of the disclosing side. Information disclosure would result in higher wholesale and thus higher retail electricity prices. (JEL L50, L94, D43)
\end{abstract}

\begin{abstract}
Ratepayers (i.e. California consumers) are aided when market participants have access to this level of [comprehensive utility planning data] information.... market participants (e.g. generators, energy service providers ...) are able to more effectively plan to meet the demands of ratepayers ... [to] develop the most efficient and cost-effective solution to meeting product demand. - Independent Energy Producers Association (2004, p. 4)

The C[alifornia] E[nergy] C[omission] does not believe that California ratepayers will be harmed by a more transparent system. . . . [it] believes all planning "facts" ought to be publicly available.

-California Energy Commission's Comments on Confidentiality of Planning and Procurement Information (2004, p. 4, p. 7)
\end{abstract}

*Funding for these experiments was provided by Southern California Edison. The authors served as consultants for Southern California Edison before the Public Utilities Commission of the State of California concerning Order Instituting Rulemaking to Establish Policies and Cost Recovery Mechanisms for Generation Procurement and Renewable Resource Development, Rulemaking 0110-024. Subsequent research support was provided by the National Science Foundation and the Caltech Laboratory for Experimental Economics and Political Science. We are grateful for the valuable comments provided by Joseph Cook of NERA, the editor, and an anonymous referee. Shakun Datta and Travis Maron provided excellent programming and research assistance.

Cason: Professor of Economics, Department of Economics, Krannert School of Management, Purdue University, 403 West State Street, West Lafayette, IN 47907-2056. Phone 1-765-494-1737, Fax 1-765-494-9658, E-mail cason@purdue.edu

Plott: Edward S. Harkness Professor of Economics and Political Science, Division of the Humanities and Social Sciences, 228-77, California Institute of Technology, Pasadena, CA 91125. Phone 1-626-395-4209, Fax 1-626-395-8580, E-mail cplott@hss.caltech.edu

\section{INTRODUCTION}

The epigraphs, taken at face value, suggest that some commentators and policy makers believe that more information about the objectives of one side of a market made available to the other side of the market always improves the advantages of the market for all. One often sees the term transparency to describe a wholesome objective for regulated markets, referring to the disclosure of private information by market participants. The belief is about the fundamental principles of price discovery in markets - that the law of supply and demand operate neutrally and more efficiently if all information is public. The belief is reflected, for example, in the "sunshine" provisions of regulatory rule making in many states, as well as advice for financial markets from the International Monetary Fund (IMF 2001). The question posed by this article is whether the basic principle is correct or whether it is actually misleading about the consequences of disclosure policies.

Is more information always better? Motivated by a dispute over information disclosure proposed for California's regulated utilities,

\section{ABBREVIATIONS}

CE: Competitive Equilibrium

CEC: California Energy Commission

EFET: European Federation of Energy Traders

IMF: International Monetary Fund

ORA: Office of Ratepayer Advocates

TURN: The Utility Reform Network 
this article presents laboratory evidence that forcing only some parties to reveal private information when bargaining with others can result in inferior terms of trade for the revealing agents. In other words, the policy advocated by the California Energy Commission and similar policy bodies are based on unreliable (indeed incorrect) principles. Forcing the utilities to reveal confidential information regarding their energy demands to suppliers leads to higher negotiated prices and ultimately higher electricity prices for California consumers. The fallacy is that greater information in markets necessarily improves market performance from the point of view of all participants. Although no detailed theory that leads to this view is offered, the fallacy itself appears to rest on a flawed interpretation of the law of supply and demand along the following lines: Efficient market equilibration is identified with the Nash equilibrium of an associated game theory model. For the game to equilibrate at an efficient Nash equilibrium, compete information about player utility functions must be necessary. Therefore, markets will work better if the utility functions are known to all. Of course, every sentence of the argument can be challenged as incorrect.

Our experiment evaluates the market implications of greater information dissemination based on a static environment without endogenous entry or exit of suppliers. The quotes for California, as well as the position of the European Federation of Energy Traders (EFET), indicate that commentators believe that one benefit of greater transparency arises through more efficient entry decisions. ${ }^{1} \mathrm{Al}-$ though the experiment does not address these long-run considerations directly, it does provide some indirect evidence that entry could be attracted by greater information dissemination because the information leads to higher prices and profits of suppliers. But if this information release ultimately leads to lower costs to the buying utilities due to increased entry, utilities should not need additional regulations to force them to reveal their planning and procurement data.

Before presenting details of the experimental design, we find it useful to first present

1. "Poor access to information raises a huge barrier to the entry of new market participants and is stifling the development of efficient, transparent wholesale markets" (EFET, 2003, p. 1). some background of the motivating controversy in the California electricity market that serves to characterize the manner in which the fallacy finds its way into important regulatory discussions. Overall, about one-third of the energy requirements of California's investorowned electric utilities are met by utilityowned generation. The remaining two-thirds is bought from independent power producers, other out-of-state utilities, and federal power projects, such as the Bonneville Power Administration. Although some of this power is bought on centralized spot markets, much is procured through short-term (a year or less) and medium-term (one to five years) contracts that are negotiated with these suppliers.

The relationship between California's electric utilities and third-party intervenors such as The Utility Reform Network (TURN) and the Office of Ratepayer Advocates (ORA) has been strained over the years, particularly recently because of the well-publicized problems with energy pricing in the state. Starting in 2002, these intervenors, supported by market participants who sell power to California utilities, sought to require the utilities to publicly release substantial amounts of short- and long-term planning data to all market participants, including all product, price, forecast, and availability information contained in the utilities' procurement-related activities and applications. The intervenors and suppliers argued that this increased the market's transparency and would operate to the benefit of the electricity-consuming public. In the utilities' opinion, however, revealing such detailed data is tantamount to revealing all of their relevant demand information to potential suppliers prior to initiating negotiations.

Through a series of hearings, administrative law judge rulings, and negotiated settlements between the utilities and the intervenors during 2002 and 2003, the utilities either agreed to or were ordered to provide some additional information that had previously been considered confidential. Some planning and forecast data, as well as short-term procurement plans, for example, are now released but with a lag of several years. Other "market-sensitive" information was not to be released. Nevertheless, in a 3 April 2003 ruling, the judges and the Public Utilities Commission expressed intent to revisit their approach governing the treatment of confidential information, to improve "transparency in resource planning." The utilities 
strongly oppose releasing more information to the suppliers, and the suppliers strongly support receiving additional information from the utilities. ${ }^{2}$

It is well recognized in economics, of course, that as long as interests of bargainers are not sufficiently integrative (i.e., are not largely aligned with common interests) then providing private information to a bargaining opponent can make the revealing party no better off. This is true of most economics problems, such as bargaining over predominantly distributive attributes like price. For example, see Kennan and Wilson (1993) for an overview of bargaining models with private information. In regulatory disputes like this, however, theoretical arguments may not carry as much weight as clear, empirical evidence. To make a clear comparison between market outcomes with and without information disclosure using field data would require at least two different regulatory territories with different disclosure rules but similar market conditions (e.g., number of utilities, suppliers, power exchanges, procurement rules, weather conditions, etc.). Therefore, an accurate empirical evaluation of the information disclosure rules, holding other market conditions constant, is not feasible with field data. Empirical evidence, however, can be provided by a laboratory study.

Our laboratory experiment consists of 17 separate market sessions. We consider five separate environments, as explained in section III. All experiments are conducted in a new laboratory trading mechanism, described in section II, meant to capture many of the salient features of a market with multilateral, private pairwise negotiations, with no public transaction price information. This provides a reasonable approximation to the process of negotiating contracts for energy in California, where only the very short-term (day ahead and hour ahead) needs are priced in centralized markets.

Section IV presents the results. We find that negotiated prices tend to favor the informa-

2. The California Energy Commission (CEC 2004) has weighed in on the side of the suppliers. Notably, the CEC also recommends that suppliers be allowed to keep their fuel prices confidential for six months, because such information provides a basis for a competitive edge among competing suppliers. That is, they argue that suppliers should be able to keep their costs private while utilities should be required to reveal more quantitative details about demand. tion advantaged side of the market; for example, prices were higher when information about buyers' demand was revealed to sellers than when information about sellers' cost was revealed to buyers. This advantage occurs both in the adjustment phase as prices are moving toward equilibrium, as well as after equilibrium is reached. We also find that when sellers have some information about demand conditions and their own costs, prices are more sensitive to changes in demand conditions than changes in supply (cost) conditions. Prices do reach competitive equilibrium and nearly all gains from trade are extracted, regardless of the information disclosure rule, so our results do not identify a short-run efficiency cost of the information disclosure. Rather, the impact of information disclosure affects the distribution of surplus. If public utility regulators are concerned about benefiting rate payers, our results indicate that this goal is not achieved by revealing demand information to sellers.

To our knowledge, this is the first experimental study that examines this type of information asymmetry in multilateral negotiations. Several previous studies, however, have introduced information asymmetries to bilateral negotiations. Murnighan et al. (1999) formed bargaining pairs and then privately provided information about both bargainers' payoff schedules to one member of the pair. The pairs negotiated over multiple dimensions, including some with distributive characteristics (like price) as well as others with integrative, cooperative characteristics. In face-to-face bargaining, the information provided to one member of the pair allowed that member to negotiate more favorable outcomes compared to a control treatment with symmetrically, partially informed bargainers. But asymmetrically informed bargainers were not able to negotiate more favorable settlements when negotiations were conducted through computer chat windows. Roth and Murnighan (1982) also compare symmetric and asymmetric information bargains struck over computerized chats, but over lottery chips for prizes of known and unknown value. They find that the asymmetrically informed member of the bargaining pair is able to earn more than his counterpart.

Srivastava et al. (2000) also asymmetrically inform one member of the bargaining pair, who negotiate only over price. Both bargainers 
know the item's cost, but only the buyer knows the value $v$ she places on the item. The researchers do not employ a control treatment with symmetrically informed bargainers, and they employ alternating offer bargaining, control beliefs over the buyer's value $v$, and vary the degree of uncertainty over $v$ as a main treatment variable. The authors employ this careful information structure because they evaluate specific predictions of the Grossman and Perry (1986) sequential equilibrium model of bargaining. Srivastava et al.'s results provide some reasonable support for key comparative static predictions, but they strongly reject the point predictions of the model.

A hint about the importance of one-sided information is found in the studies of one-sided auctions (Plott and Smith 1978; Smith 1964; Walker and Williams 1988). Although the evidence from these early studies about the role of information is tentative at best, the results reported here suggest that a review of onesided processes might be in order. The early studies do not inform traders of others' values or costs, but they systematically vary the trading institution so that one side of the market is more active and may reveal endogenously more information about their true limit prices. In the offer auction, only sellers can make price offers, and buyers can only accept offers; in the bid auction, only buyers can make price offers, and sellers can only accept these bids. Smith (1964) conducted two sessions in each of these two institution treatments, and his results suggested that prices disadvantaged the side of the market that made offers. Based on a considerably larger sample of 14 experimental sessions, however, Walker and Williams find that in early trading periods there is not a systematic price difference across institution treatments. Plott and Smith cast further doubt on the theory that information asymmetries play a key role in these particular convergence processes by demonstrating that the dynamics are exactly the opposite in the one-sided posted price markets (in which posting favors the offering side) and oral auctions (in which tendering hurts the offering side). Thus, role of information in the convergence process has remained essentially unresolved.

\section{THE TRADING INSTITUTION}

Our goal was to capture some salient features of the multilateral but private, pairwise negotiations that characterize the price discovery process in the wholesale market for electricity in California. We chose this market structure for the experiment over classical open outcry markets for three reasons. First, the fallacy just described is typically found in regulatory discussions in industries in which the industrial organization is more decentralized, with localized, private contracts much the same as the California wholesale electricity industry. Second, it is well known from the study of insiders in open outcry markets that the information held by insiders quickly disseminates throughout the market, and thus the effects of any asymmetries of information are typically small and hard to detect (Forsythe and Lundholm 1990; Plott and Sunder 1988). We wanted to study the effects in a context in which the principles at work can be more easily observed and studied. Third, in the California wholesale electricity markets, contract terms following a successful negotiation are private information, so this market does not feature any public transaction price information. Participants can negotiate simultaneously with different potential trading partners, and any agent is free to initiate or terminate negotiations with an agent on the other side of the market at any time. Clearly, therefore, the outside option for any negotiation is endogenous and is determined by trading terms available from alternative trading partners.

Most previous market experiments feature centralization of offers and/or transaction prices, so we required a new laboratory trading institution for these multilateral but private negotiations. A classic telephone market, such as the one used in Hong and Plott (1982) and in Grether and Plott (1984), could capture many of the key features of this type of negotiation process. The message space for telephone negotiations is rather rich, however, and can include intimidation, unverifiable claims, and persuasion. Therefore, we employed a computer-mediated negotiation process to increase control and limit the message space to the main variable of interest: price offers.

Figure 1 displays the main trading screen for the Marketscape program used to capture the key features of private, multilateral negotiations. Buyer 125, for example, receives price offers from sellers in his X125 Personal Market, and they are listed in ascending order in his personal sell order book shown at the lower right of the screen. He accepts the best 
FIGURE 1

Example Marketscape Trading Screen

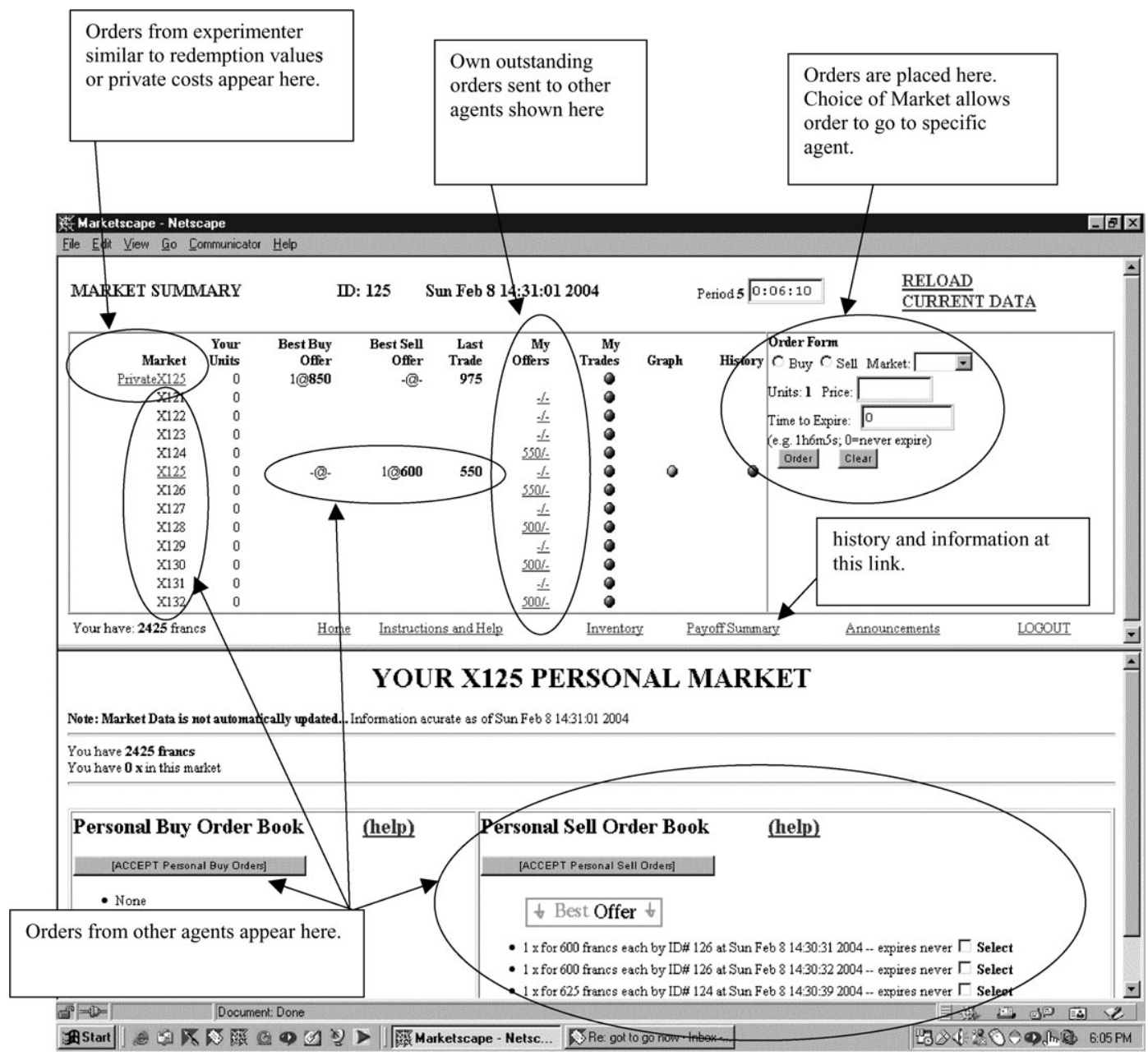

offer by clicking on a checkbox and then clicking the ACCEPT button. This buyer can also send price offers to specific sellers by filling out the order form shown on the upper right of this screen. He can revise or add additional offers and cancel any outstanding offers at any time. However, he must select only one "market" to send any offer to, and only one seller (i.e., that seller's personal market) can view those particular offers. Therefore, individual negotiations between any pair of potential traders are private, but traders can negotiate simultaneously with multiple potential trading partners. There is no public reporting of transaction prices, but traders can always access their own personal trade history.
Although this particular form of computermediated negotiation is not found in the field, where many different forms of market exist, it is relevant for the policy question that is the focus of our research. We are interested in the impact of information asymmetry on market outcomes, and this trading process carefully controls the information exchanged through bargaining. The negotiation also permits a rich exchange of price information, without allowing more difficult-to-control factors, such as bargaining personality and style, to influence results. Of course, the freeform nature of this bargaining, unlike other structured mechanisms, such as alternating offer bargaining, limits the applicability of 
most theoretical models of the bargaining process. But it more accurately represents the opportunities and constraints of the negotiation process for energy contracts.

\section{EXPERIMENTAL ENVIRONMENT AND DESIGN}

In any market, the major underlying behavioral motivations of buyers and sellers can be captured in reduced form in demand and supply curves. Thus, to the extent that buyer information is disclosed to sellers, this is similar to disclosing information about the buyers' demand curve. Of course, there are various amounts of buyer information that could be disclosed, but each piece will reveal something about the demand curve. There is a considerable range of data that the Public Utilities Commission is considering compelling utilities to reveal, but the scope of information disclosure considered is tantamount to revealing all the information sufficient to define a buyer's demand curve. Therefore, the experimental design is based on this broad degree of information revelation. Although the Commission might ultimately choose a more limited degree of information revelation, the current experimental design should shed light on the direction of general effects that can be expected if more limited amounts of information are ultimately revealed.

As is the usual case in markets, each trader knew his or her own trading motivations - that is, sellers knew their own production costs, and buyers knew their own valuations for any units they purchase. For the sessions labeled as Sellers Informed, however, the sellers all received information (available at any time through a Payoff Summary link on their computer screen) about the minimum amounts that each buyer valued each unit that they might purchase. Although the instructions indicated that buyer values could exceed these minimum revealed levels, in fact they revealed the exact buyer values. ${ }^{3}$ The fact that sellers were informed was common knowledge, but the con-

3. By indicating that the buyer values could exceed the minimum revealed, the experimenter retained the ability to increase the buyer values without announcing that such increases were taking place. Had the instructions claimed that the values were exactly the redemption values, the experimenter would have lost the ability to study the unannounced parameter changes. Design $\mathrm{C}$ features unannounced demand shifts in some periods. tent of this valuation information was only distributed to the sellers. Buyers only knew their own valuations and did not receive any information on seller costs or other buyers' values, as in the usual case. Asymmetric information was distributed analogously in sessions labeled as Buyers Informed; in these sessions, buyers all knew the maximum amount of each sellers' cost for each unit potentially supplied, but sellers only knew their own costs.

For the analysis we divide the 17 experimental sessions into 5 designs, with 2 to 5 replications for each design, as summarized in Table 1.

Design A has induced supply and demand arrays shown in Figure 2, or a similar variation with slightly different numbers of buyers and sellers. The distinguishing feature of this design is that it has a narrow range of competitive equilibrium (CE) prices, or in some cases a unique $\mathrm{CE}$ price.

Design B has supply and demand arrays shown in Figure 3. The distinguishing feature of this design is that it has a much wider range of CE prices. All prices in the interval [475, 600] are equilibrium prices in which the quantity supplied equals the quantity demanded.

Design $C$ features a variety of upward demand shifts in different periods, and one supply shift in an early period. The demand shifts are displayed in the supply and demand arrays shown in Figure 4.

Design $\mathrm{D}$ features a shift in both demand and supply in period 7 , which widens the $\mathrm{CE}$ price interval in either the downward or upward direction. Figure 5 displays the downward shift employed in two sessions; the other two sessions of this design used a mirror image upward shift in the equilibrium interval.

Design E first shifts the supply function (in period 6) and then shifts the demand function (in period 10), as shown in Figure 6.

Both designs A and B have substantial symmetries between the demand side and the supply side. We began with symmetric demand and supply conditions to control for any influences that demand and supply shapes might have on the convergence process and that might obscure the separate impact of information disclosure. ${ }^{4}$ Thus, although these curves might not reflect the conditions of

4. One of the early discoveries made using laboratory markets was that prices tend to converge from above (below) the CE when equilibrium surplus is larger for buyers (sellers) (Smith and Williams 1982). 


\section{TABLE 1}

Experimental Sessions

\begin{tabular}{|c|c|c|c|}
\hline Index & Location & Market Parameters & Disclosure Condition \\
\hline 040203 & CIT & Design A & Buyer values known to sellers \\
\hline 040204 & CIT & Design A & Buyer values known to sellers \\
\hline 040206 & CIT & Design A & Seller cost known to buyers \\
\hline 040207 & CIT & Design A & Seller cost known to buyers \\
\hline 040208 & CIT & $\begin{array}{l}\text { Design D, upward shift in equilibrium in } \\
\text { period } 7\end{array}$ & Buyer values known to sellers \\
\hline 040213 & Purdue & Design $B$ set 2 & Buyer values known to sellers \\
\hline 040214 & CIT & Design $B$ set 3 & Buyer values known to sellers \\
\hline $040215 a$ & Purdue & Design $B$ & Seller cost known to buyers \\
\hline $040215 b$ & CIT & Design $B$ & Seller cost known to buyers \\
\hline $040215 \mathrm{c}$ & Purdue & Design $\mathrm{B}$ & Buyer values known to sellers \\
\hline 040216a & CIT & $\begin{array}{l}\text { Design } C \text { set } 4 b \text { schedule } 3 \text { demand shifts } \\
3,4,5,8\end{array}$ & $\begin{array}{l}\text { Buyer values known to sellers } \\
\text { periods } 5,9\end{array}$ \\
\hline $040216 b$ & Purdue & $\begin{array}{l}\text { Design } C \text { set } 4 b \text { schedule } 3 \text { demand shifts } \\
3,4,5,8\end{array}$ & $\begin{array}{l}\text { Buyer values known to sellers } \\
\text { periods } 5,9\end{array}$ \\
\hline 040229a & Purdue & $\begin{array}{l}\text { Design } \mathrm{D} \text {, downward shift in equilibrium in } \\
\text { period } 7\end{array}$ & Buyer values known to sellers \\
\hline $040229 b$ & CIT & $\begin{array}{l}\text { Design } D \text {, downward shift in equilibrium in } \\
\text { period } 7\end{array}$ & Buyer values known to sellers \\
\hline 040301 & Purdue & $\begin{array}{l}\text { Design D, upward shift in equilibrium in } \\
\text { period } 7\end{array}$ & Buyer values known to sellers \\
\hline 040308 & Purdue & $\begin{array}{l}\text { Design E, supply shift per. } 6 \text {, demand shift } \\
\text { period } 10\end{array}$ & Buyer values known to sellers \\
\hline 040309 & Purdue & $\begin{array}{l}\text { Design E, supply shift per. } 6 \text {, demand shift } \\
\text { period } 10\end{array}$ & Buyer values known to sellers \\
\hline
\end{tabular}

the California electricity market, they do allow us to study how the proposed information revelations will influence the functioning of the fundamental laws of supply and demand.
Design C serves two functions. First, it is a robustness check on the overall patterns of results derived from the other designs. The design involves a series of demand and supply

FIGURE 2

Supply and Demand for Design A

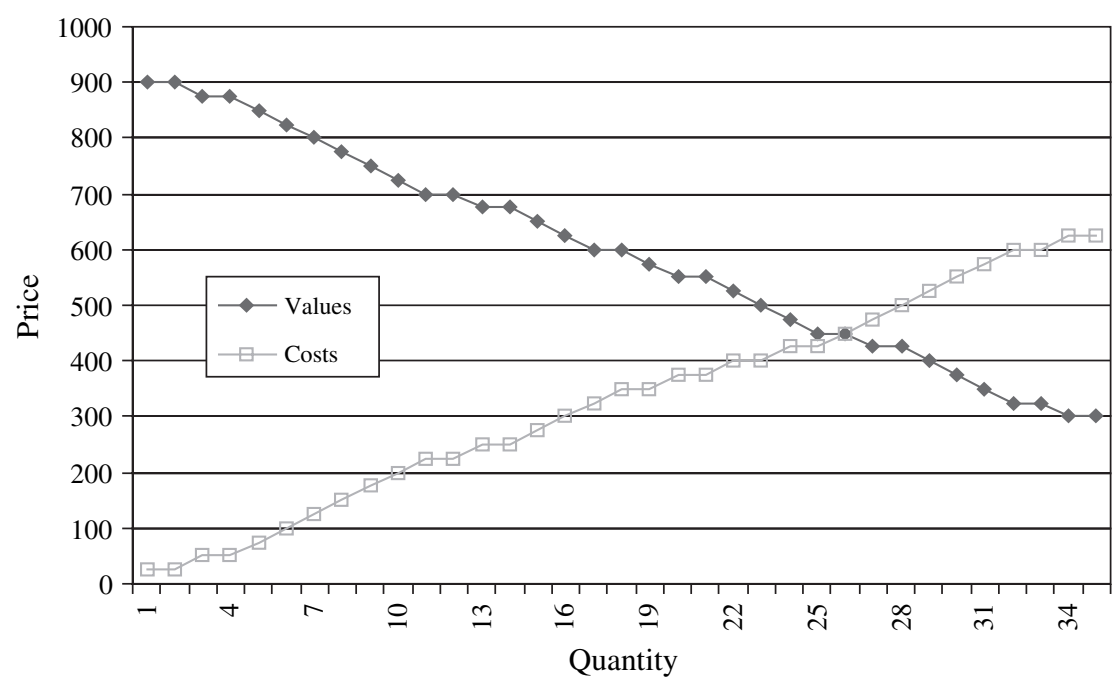


FIGURE 3

Supply and Demand for Design B

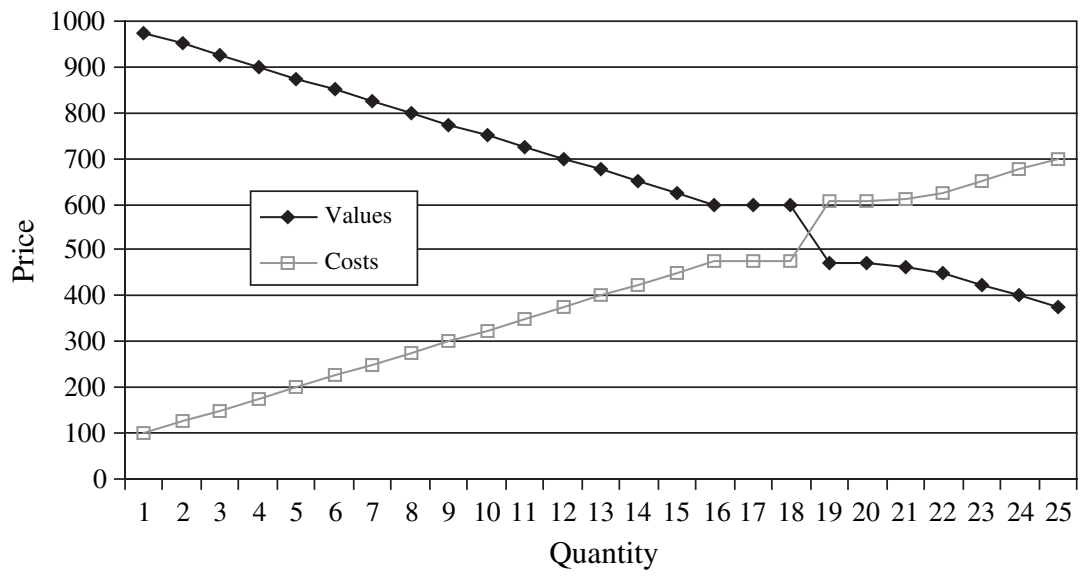

shifts rather than the single demand or supply shifts of the other design. It also incorporates information revelation about demands and supplies that are not coincident with parameter changes, so information shifts that might be contained in market activity alone is not confounded with the information provided through regulations to one side of the market or the other. Second, the design is especially relevant for exploring the issues of the California electricity market. In this design, the supply curves used in the experimental markets have important qualitative features that broadly correspond to the features found in electricity markets. Supply is "flat" over a broad range and then turns upward sharply as capacity limits are approached. Demand, on the other hand, is very inelastic and grows from one period to the next. These are important similarities with the situation that can be expected to evolve in California as demand for electricity grows due to growing population, short-run supply is inelastic, and the elasticity of long-run supply is highly uncertain due the financial stress in the generation development market. Thus the design tests for the possibility that the particular parameters present in the regulatory dispute that partially motivates the study do not have implications for the principles that are at work.

Designs D and E, like designs $\mathrm{A}$ and $\mathrm{B}$, are not intended to be consistent with specific underlying properties of the California

FIGURE 4

Supply and Demand for Design C

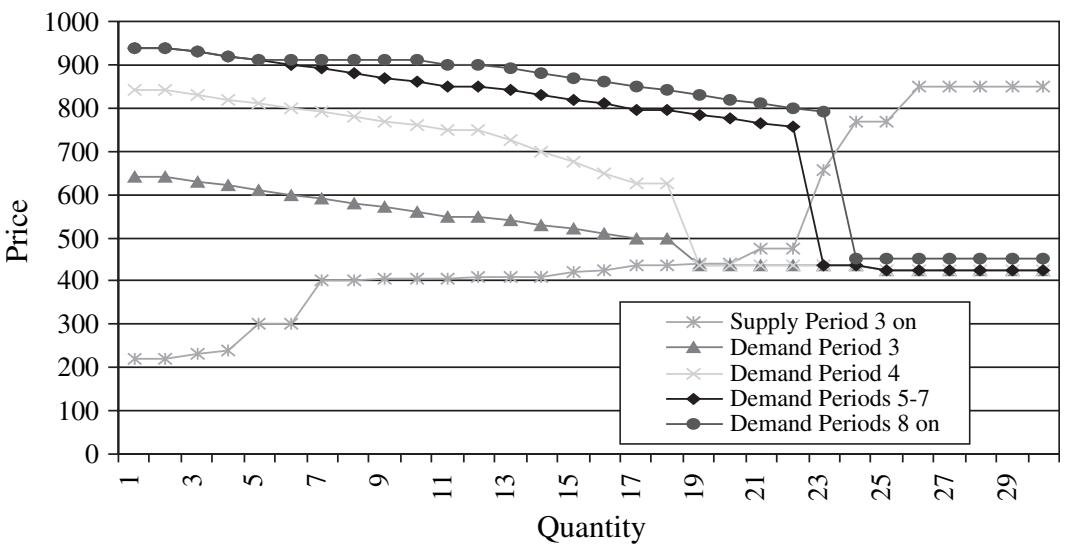


FIGURE 5

Supply and Demand for Design D

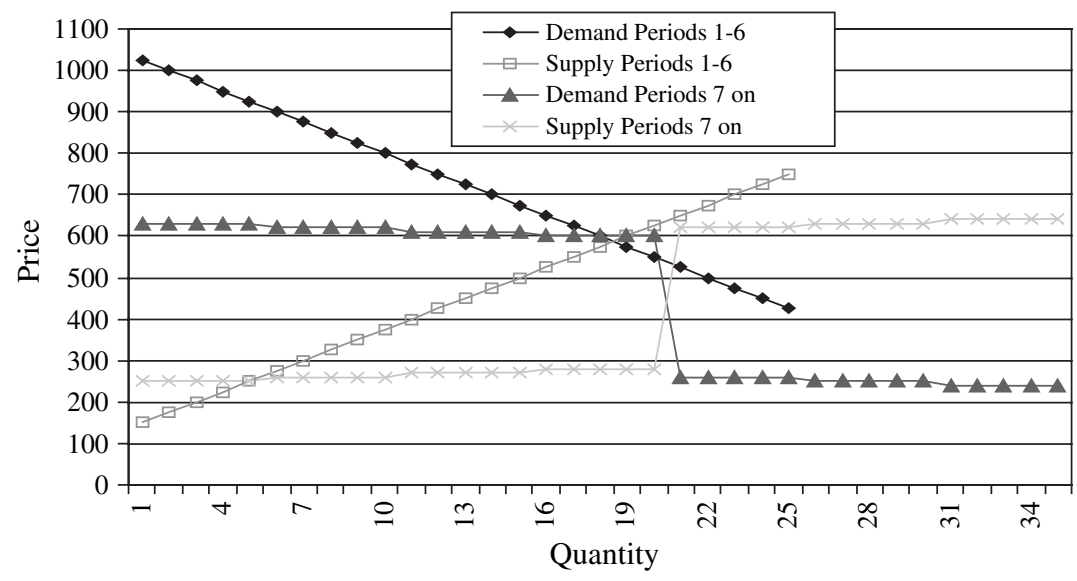

electricity market. Instead, we chose these parameters to investigate further how the information advantage enjoyed by one side of the market affects adjustment to new equilibrium conditions. The designs also provide insight into how information is disseminated through bargaining in this multilateral negotiation institution.

The other variable that we systematically changed from one experimental session to another was whether the supply side or the de- mand side of the market was asymmetrically blessed with knowledge about the other side. In 13 of the 17 sessions, the sellers were given detailed information about the minimum value that units were worth to buyers. For shorthand we refer to these as Sellers Informed sessions. In the two design $\mathrm{C}$ sessions, the sellers received this information in period 5 , and it was not updated until period 9 . In the other sessions, the sellers received this information before the first period, and they were continually

FIGURE 6

Supply and Demand for Design E




kept up to date about changing information about the buyers.

Although it is not the current issue in California, for an understanding of the symmetry in the other four sessions the buyers were given detailed information about the maximum cost that sellers incurred to produce units. We refer to these as Buyers Informed sessions, which can be used as controls to identify the effect of information disclosures.

As highlighted in Table 1, about one-half of the sessions were conducted at Caltech and one half at Purdue University. We employ site dummy variables in some of the analyses reported below, but we did not identify any statistically significant differences in outcomes across sites. All sessions used the identical Marketscape trading program, running on a server located in the Caltech lab. All subjects underwent substantial Marketscape training prior to participating in these sessions, which included practice negotiation and trading with robot trading partners. This training lasted more than an hour, and it occurred either immediately before the session or some days or weeks prior. The specific instructions for the sessions reported here, available online at www.krannert.purdue.edu/faculty/cason/ papers/fallacy_inst.pdf, were distributed to subjects and read orally by the experimenter while displayed on an overhead projector. Period 1 of each session (not reported) was a practice period that did not count in the subjects' final cash earnings. The exchange rate of experimental currency to dollars varied across design parameters, calibrated to provide average earnings than ranged from about $\$ 25$ to $\$ 40$ for the sessions that lasted between 2 and 2.5 hours.

\section{RESULTS}

Our first result confirms that the general market convergence properties observed in previous auction-type and exchange-type experimental markets also operates in these bilateral-negotiation markets. ${ }^{5}$

5. All of the results exclude the small number of transactions that were clearly typographical errors because they differed from other transaction prices by at least one order of magnitude; for example, a price of 57 when all recent transaction prices ranged between 575 and 600. This excludes 48 of the 3351 transactions in the 17 sessions $(1.4 \%)$. Although these excluded transactions could influence subsequent transactions in the same session, our lack of public price information (due to the private bilateral trading institution employed) considerably limits their impact.
TABLE 2

Deviations of Median Transaction Prices from Competitive Equilibrium

\begin{tabular}{|c|c|c|c|c|}
\hline $\begin{array}{l}\text { Session } \\
\text { Index }\end{array}$ & $\begin{array}{c}\text { Period } 2 \\
\text { Median-CE } \\
\text { (1) }\end{array}$ & $\begin{array}{c}\text { Period 5 } \\
\text { Median-CE } \\
\text { (2) }\end{array}$ & $\begin{array}{c}\text { Difference } \\
\text { in Absolute } \\
\text { Deviations } \\
\text { (Period 2 - } \\
\text { Period 5) } \\
\text { (3) }\end{array}$ & $\begin{array}{c}\text { Period 5 } \\
\text { Efficiency } \\
\text { (4) }\end{array}$ \\
\hline \multicolumn{5}{|l|}{ Design $A$} \\
\hline 040203 & 50 & 0 & 50 & $97.1 \%$ \\
\hline 040204 & 49 & 50 & -1 & $98.0 \%$ \\
\hline 040206 & 0 & 0 & 0 & $98.7 \%$ \\
\hline 040207 & -25 & -15 & 10 & $96.3 \%$ \\
\hline \multicolumn{5}{|l|}{ Design $B$} \\
\hline 040213 & 0 & 0 & 0 & $100 \%$ \\
\hline 040214 & 0 & 0 & 0 & $98.7 \%$ \\
\hline $040215 \mathrm{c}$ & 0 & 0 & 0 & $98.3 \%$ \\
\hline $040215 \mathrm{a}$ & 0 & 0 & 0 & $84.8 \%$ \\
\hline $040215 b$ & 0 & 0 & 0 & $98.4 \%$ \\
\hline \multicolumn{5}{|l|}{ Design $D$} \\
\hline 040208 & -25 & 0 & 25 & $99.2 \%$ \\
\hline 040301 & 0 & 0 & 0 & $99.4 \%$ \\
\hline 040229a & -25 & 0 & 25 & $98.8 \%$ \\
\hline $040229 b$ & 0 & 0 & 0 & $99.7 \%$ \\
\hline \multicolumn{5}{|l|}{ Design $E$} \\
\hline 040308 & 0 & 0 & 0 & $86.4 \% *$ \\
\hline 040309 & -25 & -22.5 & 2.5 & $95.7 \%$ \\
\hline
\end{tabular}

* Low efficiency in period 5 of this session was due to an error made by a buyer who failed to redeem a purchased unit before time expired. Efficiency would have been $97.2 \%$ if this buyer had redeemed this single unit.

\section{Result 1}

Prices in the bilateral negotiation markets converge to a competitive equilibrium under stable supply-demand conditions: (1) average prices approach the competitive equilibrium level, (2) the variance of prices across contracts declines over time, and (3) trading efficiency approaches $100 \%$.

Support. Despite the decentralized nature of trading and price information, prices move toward and usually reach the CE price range in the sessions reported here. Early prices are volatile and many are significantly lower than the equilibrium price range, but eventually most prices are within the equilibrium range. Table 2 summarizes the deviations of the median prices from the $\mathrm{CE}$ for all sessions that began with at least five periods of stable supply and demand conditions (that is, all designs 
FIGURE 7

Price Dispersion, by Treatment, Prior to First Supply or Demand Shift (Average Standard Error of the Mean Transaction Price)

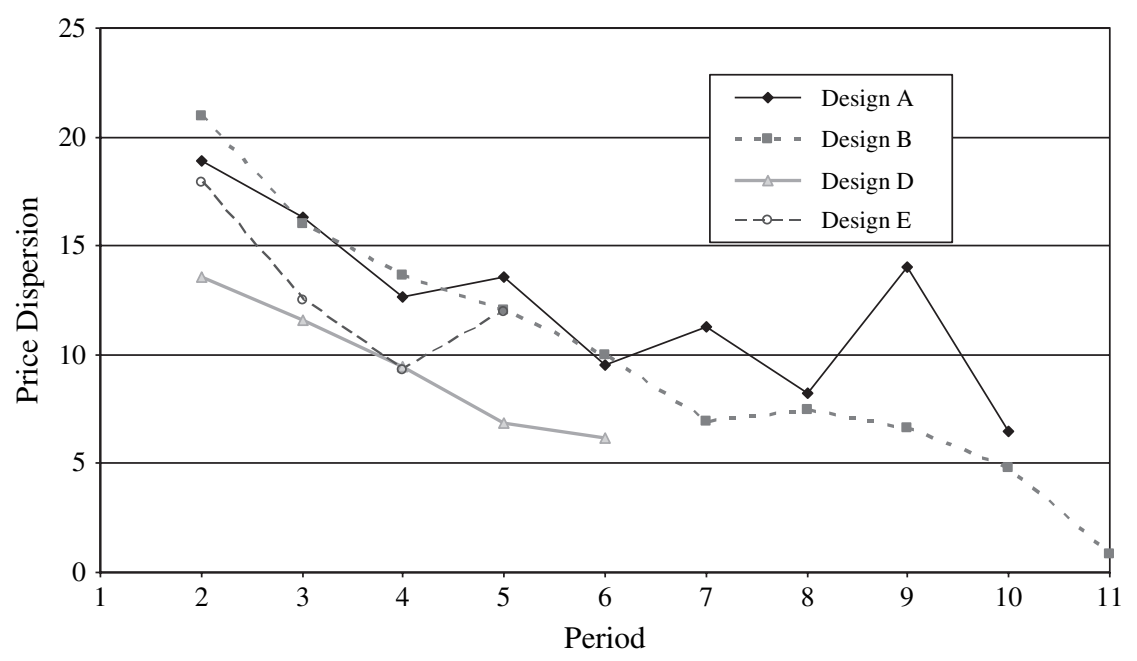

except design C). Column 1 displays the deviations of the median transaction price in the first paying period (period 2), and column 2 displays the deviations in period 5. All median prices lie within the wide equilibrium price interval in design $\mathrm{B}$, but period 2 median prices frequently deviate from the equilibrium in the other designs. The median absolute deviations decline significantly from period 2 to period 5 , based on the 15 statistically independent pairwise differences shown in column 3 (nonparametric Wilcoxon signed rank test $p$-value $=$ 0.031, one-tailed).

Price movements toward the CE interval are clearly evident in Table 2 . However, by convergence in these types of markets, we mean more than simply a tendency for average or median prices to approach the equilibrium level. In addition to average prices that approach equilibrium, convergence also requires price dispersion to decline toward zero. That is, we expect the "law of one price" to prevail in markets that have converged. Figure 7 presents evidence on this dimension of convergence. The figure displays the standard errors of the mean associated with the average transaction prices up until the first shift in supply and demand, averaged across all sessions within each treatment (except design C). In most sessions the price dispersion, as shown on the vertical axis, is high during the early periods. As the periods progress the dispersion falls dramatically in the sense that early dispersion is on the order of two to five times that of later periods. In other words, competitive pressures are bringing the prices together, even though price information is never publicly displayed and traders can only infer prices through their bilateral negotiations with other traders. Another convergence criteria often used when analyzing laboratory markets is increasing trading efficiency. Trading efficiency is defined as the percentage of maximum (CE) trading surplus realized in the market. As shown in column 4 of Table 2, our markets were highly efficient, with period 5 efficiencies typically in the $95-100 \%$ range.

The next result presents the most important conclusion from the experiment: the relationship between pricing outcomes and the asymmetric distribution of information.

\section{Result 2}

Information confers a pricing advantage, particularly during the equilibration phase of market interactions when prices are adjusting toward equilibrium.

Support. Consider Figures 8 and 9, which show the median transaction prices for each period and each session in designs $\mathrm{A}$ and $\mathrm{B}$. The Buyers Informed sessions are identified with the triangle and the cross in both figures. 
FIGURE 8

Median Transaction Prices by Session, Design A

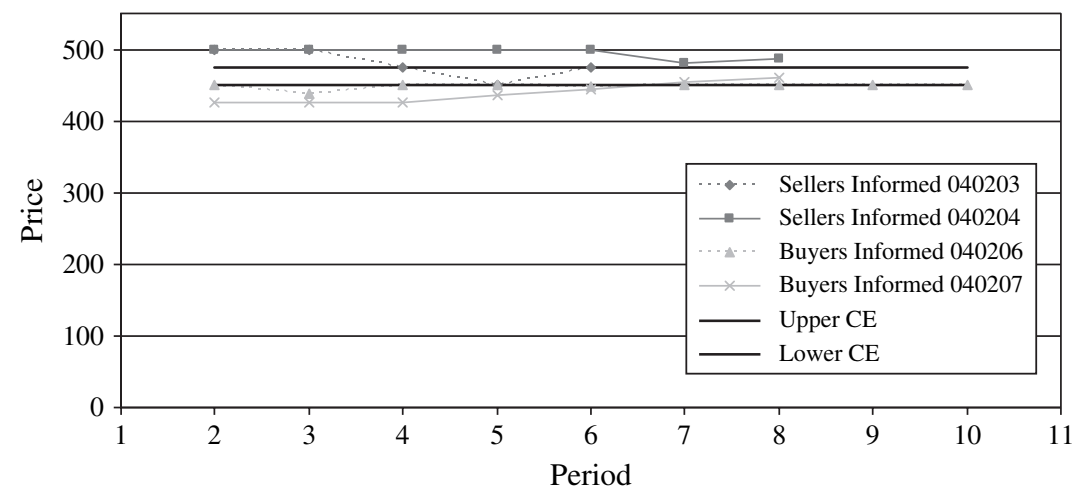

Note: Upper CE of 475 only applies to session 040207. Other sessions have a unique CE of 450 (shown as Lower CE).

In design A (Figure 8), for all periods except one the maximum median price in any Buyers Informed session is lower than the minimum median price in any Sellers Informed session. Pooling the data in design A across sessions and periods, we find that prices are on average $7 \%$ higher when sellers are informed (484) than when buyers are informed (453). Likewise, in design B (Figure 9), median transaction prices are also usually higher in the Sellers Informed sessions than in the Buyers Informed sessions. Pooling across sessions and periods in design $\mathrm{B}$, prices are on average
$8 \%$ higher when sellers are informed (555) than when buyers are informed (516).

Prior to the midsession shift, design $\mathrm{D}$ has the same supply and demand configuration as design A. This design therefore provides four additional sessions (all with sellers informed) to add to the nine design $\mathrm{A}$ and $\mathrm{B}$ sessions shown in Figures 8 and 9 for a statistical comparison of prices in the two information treatments. For this comparison we use the period 5 (median price - competitive equilibrium price midpoint) deviations for each session in designs $\mathrm{A}, \mathrm{B}$, and $\mathrm{D}$ to provide comparable

FIGURE 9

Median Transaction Prices by Session, Design B




preshift prices in all sessions. These deviations are positive in only one of the four Buyers Informed sessions, but are positive in five of the nine Sellers Informed sessions. A nonparametric Mann-Whitney test, based on the 13 statistically independent session observations, marginally rejects the hypothesis that these period 5 deviations are not different in the two treatments in favor of the one-sided alternative that prices are higher when sellers have some information about buyer values ( $p$-value $=$ 0.087, $N_{A}=9, N_{B}=4$ ). We draw a similar conclusion from a simple cross-sectional ordinary least squares regression that employs one period 5 price deviation observation per session, which allows us to control for design differences with a design B dummy variable and experimental site differences with an (insignificant) Purdue dummy variable. The point estimate indicates a 24 franc higher median price when sellers are informed (SE 13.3, one-tailed $p$-value $=0.053){ }^{6}$

\section{Result 3}

The pricing advantage provided by the asymmetric disclosure of information often declines as prices approach the equilibrium, but the pricing advantage can persist when a wide range of equilibrium prices exists.

Support. Figures 8 and 9 indicate that the price differences between Buyers Informed and Sellers Informed sessions are generally more pronounced in the early periods than in the later periods. For example, consider the size of the percentage price difference across these two opposite cases for the first three paying periods (periods 2 through 4 ) compared to the next three paying periods (periods 5 through 7). In design A (i.e., narrow range of equilibrium prices), the differences in prices across treatments are modestly greater in periods $2-4$ (averaging $8.1 \%$ ) compared to

6. We obtain similar results if we replace the median price dependent variable with a variable representing seller profits. In particular, define Relative Seller Profit as the aggregate seller earnings divided by the earnings that sellers would receive if all efficient trades occurred and took place at the CE price midpoint. This normalization adjusts seller profits for the differing supply and demand conditions across sessions. A regression of period 5 Relative Seller Profit on the disclosure rule, design and site dummy variables indicates a point estimate of $13 \%$ higher Relative Seller Profit when sellers rather than buyers are informed $(\mathrm{SE} 8.6$, one-tailed $p$-value $=0.079)$. periods 5-7 (averaging 6.7\%). But in design B (i.e., wider range of equilibrium prices), in periods $2-4$ the prices are on average $10.1 \%$ higher when sellers are informed (544) than when buyers are informed (494), whereas in periods 5-7 the prices on average are only $5.3 \%$ higher when sellers are informed (558) than when buyers are informed (530).

Nevertheless, an independent examination of the longer design B sessions 040215a and $040215 \mathrm{c}$ indicate that the pricing advantage can persist even after prices have converged to equilibrium, as long as that equilibrium contains a relatively wide range of prices. In the late periods $8-10$, the average transaction price in the Sellers Informed session 040215c is $9 \%$ higher (581) than in the Buyers Informed session 040215a (532). Note that both of these averages are, however, still within the range of equilibrium prices $[475,600]$.

\section{Result 4}

The response of realized transaction prices to changes in equilibrium market conditions depends on the information available to traders about the new supply and demand situation. (1) Design D sessions show that when both types of traders can recognize an underlying shift, prices adjust toward the midpoint of the new equilibrium price range; (2) design $\mathrm{E}$ sessions show that prices do not adjust to reflect cost reductions when only sellers are aware of the underlying change in market conditions.

Support. Figures 10 and 11 present median transaction prices for the 6 sessions in Designs $\mathrm{D}$ and $\mathrm{E}$. Sellers were informed of the minimum buyer values in all six of these sessions. In design $\mathrm{D}$ a narrow market equilibrium price range in early periods is followed by a large demand and supply shift in period 7 to a condition that results in both inelastic demand and inelastic supply and a wide range of equilibrium prices. After the shift, however, prices that were very near the old equilibrium price remain as possible new equilibrium prices. Thus, because we observe prices in the equilibrium range - as documented throughout these results - a possibility exists that prices would move very little or by a substantial amount (up to $50 \%$ ) after the shift is introduced in period 7 .

Despite the possibility that prices need not adjust by much to reach a new equilibrium level, however, prices in fact adjust quickly 
FIGURE 10

Median Transaction Prices by Session, Design D

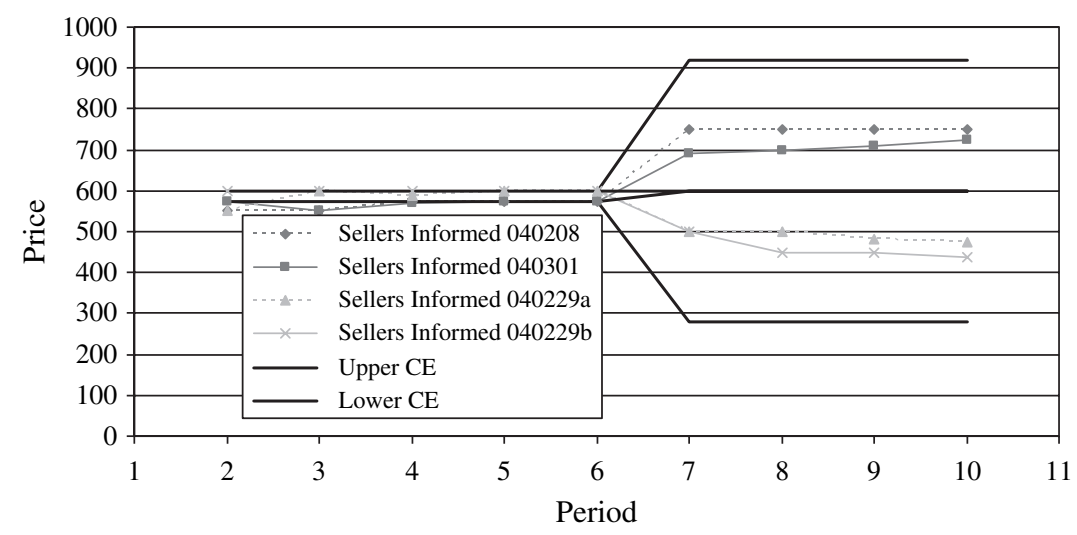

and significantly to near the middle of the new equilibrium price range. What is perhaps more surprising is that the shift is similar in speed and size when the equilibrium shifts down compared to when it shifts up, even though in all four sessions sellers have some information about the buyers' values and buyers never know the sellers' costs. Buyers can infer that market conditions are changing in period 7 , though, because of their own dramatically revised resale values. This may have motivated them to negotiate aggressively with sellers following the shift, leading to substantial downward price pressure when the equilibrium price range shifted all the way down to 280 francs. This conjecture motivated the more subtle supply and demand shifts introduced in design E.
In design E, sellers' costs shifted down in period 6 , resulting in a downward widening of the competitive equilibrium price interval. Buyers' values remained unchanged, and they received no information about sellers' costs, so they should have been unaware of the supply shift. Although prices could have fallen by as much as $20 \%$ following this shift and still remain in the equilibrium range, Figure 11 shows that median prices hardly adjust (remaining mostly around 700 francs) in both sessions. By contrast, median prices increase immediately in both sessions when a demand shift that is known to the informed sellers is introduced in period 10 , and prices continue to rise thereafter. This suggests that when sellers are asymmetrically informed about buyer values,

FIGURE 11

Median Transaction Prices by Session, Design E

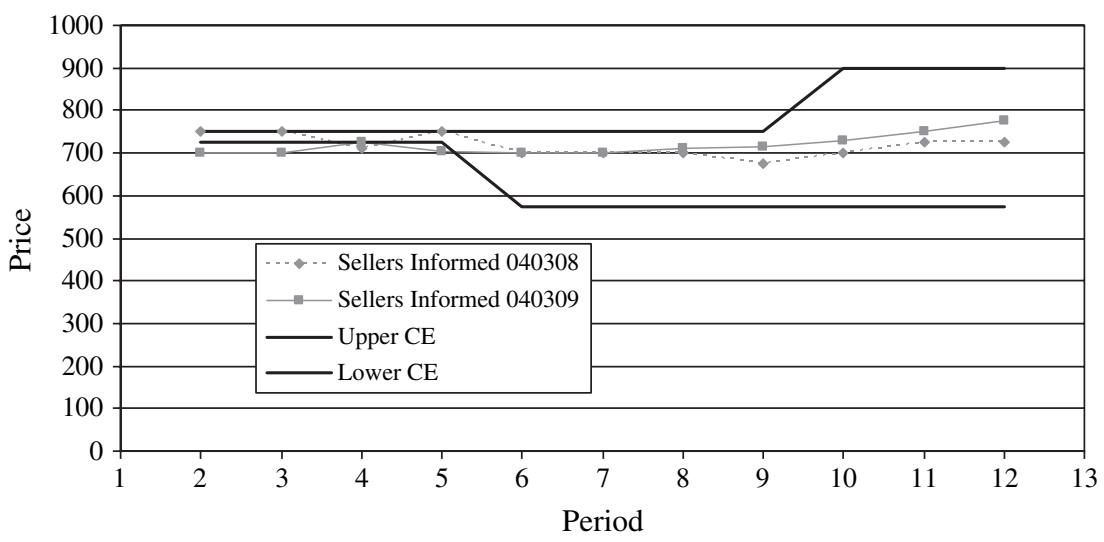


FIGURE 12

Median Transaction Prices by Session, Design C

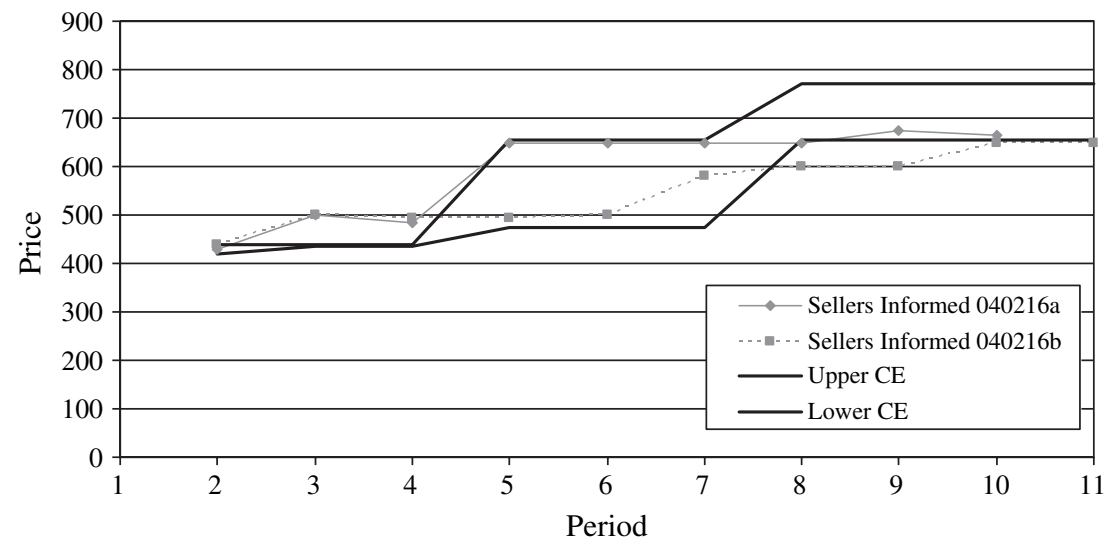

the transaction prices are more sensitive to demand shifts than they are to supply shifts.

\section{Result 5}

All results stated previously survive the robustness tests of series $\mathrm{C}$.

Support. Series C consists of two sessions operating under the same parameters. The time series of median transaction prices are displayed in Figure 12. In these sessions the first two periods have stationary, symmetric demand and supply with consumer surplus equal to producer surplus. Prices converge to near the competitive equilibrium by period 2 , consistent with Result 1 . In period 3 a demand and supply shift takes place that is not announced to any traders. As can be seen prices move up, possibly reflecting the asymmetric rents, with consumer surplus greater than producer surplus and the market in the early part of adjustment feeling the changes with a consequent shift upward in price. In period 4 another upward demand shift takes place that exacerbates this rent asymmetry but does not affect the equilibrium price range. The information of the shift is not given to the sellers, and there is no tendency for prices to move upward, consistent with Result 2 that the information disclosure is a key feature that conveys advantages to the information receiving side. In period 5 another upward shift in demand takes place, this time widening the equilibrium price range. At the beginning of the period, some information about the demand is disclosed to the sellers, and consistent with Result 2 the prices immediately jump in one market and move sharply upward in the other market two periods later. In period 8 another upward demand shift takes place without information disclosure. This shift in demand has no effect on market prices in session 040216a and a small effect in session $040216 \mathrm{~b}$, but because the $040216 \mathrm{~b}$ market had an upward drift in prices anyway, attribution to the demand shift is problematic. In period 9 when some information about demand is disclosed and sellers learn of the shift, the market prices immediately respond upward in session 040216a, and median prices respond upward with a one-period lag in session $040216 \mathrm{~b}$. The phenomena identified in all of the previous results are also found in this more complex setting thereby demonstrating that the results are robust to such environmental changes.

\section{CONCLUSION}

This research was motivated by a proposition about a basic principle that governs market behavior that is widely asserted in regulatory settings. The proposition is that disclosure of plans and market strategies by one side of a market to the other side will be helpful to market performance and beneficial to all of the market participants. The proposition reflects a belief about how the laws of supply and demand work and the manner in 
which information works to facilitate their operation. The results of the experiments demonstrate that such a proposition is not correct. In the context of market transactions, such disclosures damage the disclosing party. The laws of supply and demand follow a completely different set of principles from those on which the proposition rests.

In the case of the California wholesale electricity market, the proposition holds that electricity prices will be lower to the consuming public if the major electricity demanders would make their demand function known to suppliers prior to contracting. The experiments demonstrate that the presumption should be that opposite would be the case. Disclosure of the demand information would result in a tendency for prices to increase, especially in the cases in which demand and supply are both inelastic and in which demand is changing, as is expected to be the case in California in the future.

Is it the case that the California wholesale electricity market is special in the sense that the law of supply and demand would work completely differently than the way that it is observed at work in the laboratory? Currently neither general theory nor institutional fact has been advanced to suggest anything other than a presumption that the basic principles operate in California in the same way that they are assumed to work in general. Indeed, advocates of the forcing of information revelation have produced no theory at all and instead have advanced the proposition as if it is completely general, applicable to all markets. Thus, the experiments produced here place a burden on the advocates to produce a theory of sufficient generality to support the proposition that they advance. When that is done, additional tests can be performed to test its reliability.

\section{REFERENCES}

California Energy Commission. Comments on Confidentiality of Planning and Procurement Information. Order Instituting Rulemaking to Establish Policies and Cost Recovery Mechanisms for Generation Procurement and Renewable Resource Development. Rulemaking 01-10-024, 27 February 2004.
European Federation of Energy Traders (EFET). Position Paper: Transparency and Availability of Information in Continental European Wholesale Electricity Markets. 2003. Available online at www.efet.org/ positionpapers/emit_position_paper_july_2003.doc.

Forsythe, R., and R. J. Lundholm,. "Information Aggregation in an Experimental Market." Econometrica, 58, 1990, 309-47.

Grether, D., and C. Plott. "The Effects of Market Practices in Oligopolistic Markets: An Experimental Examination of the Ethyl Case." Economic Inquiry, 22, 1984, 479-507.

Grossman, S., and M. Perry. "Sequential Bargaining under Asymmetric Information." Journal of Economic Theory, 39, 1986, 120-154.

Hong, J., and C. Plott. "Rate Filing Policies for Inland Water Transportation." Bell Journal of Economics, 1982, 1-19.

Independent Energy Producers Association. Comments of the Independent Energy Producers Association Concerning Data Confidentiality. Order Instituting Rulemaking to Establish Policies and Cost Recovery Mechanisms for Generation Procurement and Renewable Resource Development. Rulemaking 01-10-024, 1 March 2004.

IMF (International Monetary Fund). Transparency. Issue Brief 01/05, Washington, D.C., 2001. Available online at www.imf.org/external/np/exr/ib/2001/ 042601b.htm.

Kennan, J., and R. Wilson. "Bargaining with Private Information." Journal of Economic Literature, 31, 1993, 45-104.

Murnighan, J. Keith, L. Babcock, L. Thompson, and M. Pillutla. "The Information Dilemma in Negotiations: Effects of Experience, Incentives, and Integrative Potential." International Journal of Conflict Management, 10, 1999, 313-39.

Plott, C., and V. Smith. "An Experimental Examination of Two Exchange Institutions." Review of Economic Studies, 45(1), 1978, 133-53.

Plott, C., and S. Sunder. "Rational Expectations and the Aggregation of Diverse Information in Laboratory Security Markets.” Econometrica, 56, 1988, 1085-1118.

Roth, A., and J. K. Murnighan, "The Role of Information in Bargaining: An Experimental Study." Econometrica, 50, 1982, 1123-42.

Smith, V. "The Effect of Market Organization on Competitive Equilibrium." Quarterly Journal of Economics, 78, 1964, 181-201.

Smith, V., and A. Williams. "The Effects of Rent Asymmetries in Experimental Auction Markets." Journal of Economic Behavior and Organization 3, (1982) pp. 99-116.

Srivastava, J., D. Chakravarti, and A. Rapoport. "Price and Margin Negotiations in Marketing Channels: An Experimental Study of Sequential Bargaining under One-Sided Uncertainty and Opportunity Cost of Delay." Marketing Science, 19, 2000, 163-84.

Walker, J., and A. Williams. "Market Behavior in Bid, Offer and Double Auctions: A Reexamination." Journal of Economic Behavior and Organization, 9, 1988, 301-14. 